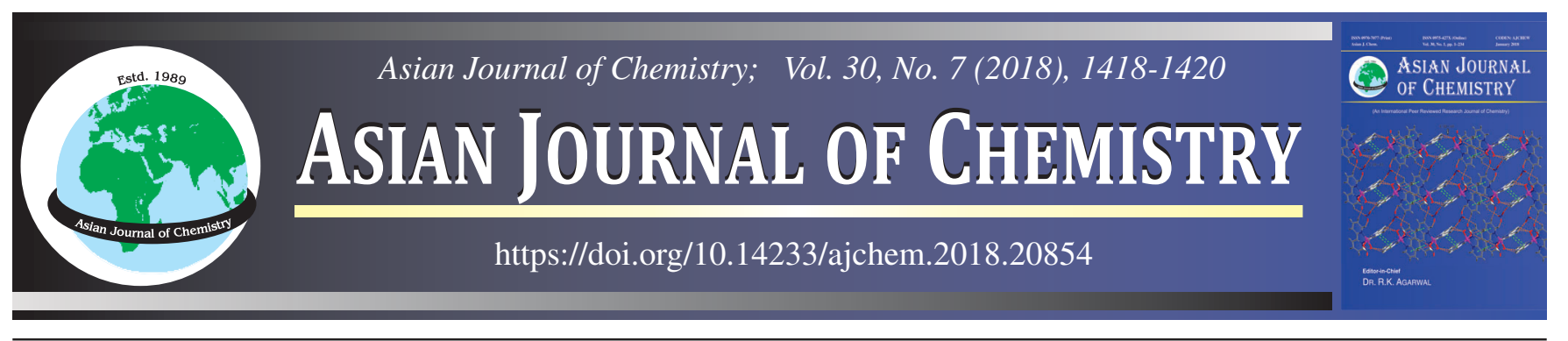

\title{
Separation and Determination of Cadmium(II) in Wastewater by Bisolvent of Ester and Ionic Liquid Flotation System
}

\author{
Yanmin Hou*, XinYaO Li and XiaOJUn ZhaO
}

Chemical and Environmental Engineering, Pingdingshan University, Pingdingshan, P.R. China

*Corresponding author: E-mail: hympdsu@ 163.com

Received: 10 June 2017;

Accepted: 10 May 2018;

Published online: 31 May 2018;

AJC-18905

\begin{abstract}
In this study, the flotation technology was used to separate and enrich the heavy metal $\mathrm{Cd}^{2+}$ ions. Based on literature, it was found that $\mathrm{Cd}^{2+}$ could form $\mathrm{CdI}_{4}{ }^{2-}$ with $\mathrm{KI}$ in solution and then $(\mathrm{RhB})_{2}\left(\mathrm{CdI}_{4}\right)$ was occurred when $\mathrm{CdI}_{4}{ }^{2-}$ was mixed with rhodamine B. This ternary associate was determined by bisolvent of ester and ionic liquid flotation system. Ionic liquid was $\left[\mathrm{Bmim}^{\mathrm{B}} \mathrm{BF}_{4}\right.$, the optimal amount of acetic acid, potassium iodide and rhodamine $\mathrm{B}$ was 8,20 and $4 \mathrm{~mL}$, respectively. The best removal efficiency obtained at a flotation time of $15 \mathrm{~min}$ with air flow rate of $30 \mathrm{~mL} / \mathrm{min}$ and $38 \%$ mass fraction of $\left(\mathrm{NH}_{4}\right)_{2} \mathrm{SO}_{4}$ solution was $95.68 \%$. The experimental data indicated that the ionic liquid have more excellent function than the traditional organic solvents.
\end{abstract}

Keywords: Separation, Ester, Ionic Liquid, Cadmium(II), Wastewater, Flotation system.

\section{INTRODUCTION}

The cadmium is one of the important water pollutants, emitted from the sources such as smelting, metal plating, cadmiumnickel batteries, phosphate fertilizers, pigments, stabilizers, alloy industries [1]. Cadmium is a toxic metal occurring naturally in the environment and considered as a pollutant emanating from industrial and agricultural sources. Exposure of human population to cadmium from air, food and water may produce effects in organs such as kidney, liver, lung and cardiovascular, immune and reproductive systems [2]. Determination of cadmium trace elements in water is still one of the tedious job in analytical chemistry and it requires highly sensitive and accurate analytical methods [3]. Various methods based on solvent extraction [4], ion exchange [5], membrane filtration [6], cloud point extraction [7-9], coprecipitation [10,11] and solid phase extraction $[12,13]$ have been developed for the pre-concentration of trace elements in water samples.

Compared to the above methods, the organic solventsflotation (OSFS) system have many advantages, for example, high efficiencies ( $\mathrm{R}>95 \%$ ), rapidity, a large enrichment factor, lower detection limits, and a simple and convenient process, the possibility of removal and recovery of organic and inorganic species. But there is a problem that the organic solvent could pollute water in environment. The ionic liquids which is a kind of green and environment friendly solvent instead of organic solvents have solved this problem. The ionic liquid-flotation system (ILFS) not only possess the advantages of organic solventsflotation system (OSFS), but also has more outstanding advantages viz., higher efficiency, stronger stability, environmental protection, no pollution, more separating property and greater enrichment factor. Therefore, in this research, the ionic liquidflotation system (ILFS) has been developed and used to separate and determine the cadmium element of wastewater.

Room temperature ionic liquids (RTILs) are a group of new organic salts consisting of organic cations and various anions that are liquids at room temperature $[14,15]$. There are as many as 1018 kinds of ionic liquids available in literature [16]. Recently, room temperature ionic liquids with unique properties such as negligible vapour pressure, water stability, favourable viscosity and density characteristics, good thermal stability, non-volatility and good selective solubility have been used as alternative solvents separation purposes $[17,18]$.

For the past several years, the research of flotation which is applied on the environmental water treatment is just unfolding. Flotation is a separation process and its main advantages are: high efficiencies ( $\mathrm{R}>95 \%$ ), rapidity, the possibility of removal and recovery of organic and inorganic species. Several studies indicate that heavy metal separation is the important topics for $21^{\text {st }}$ century [19]. In this study, ionic liquid based solvent flotation (ILSF) for the extraction of cadmium(II) in wastewater was developed. The traditional hydrophilic organic solvent was replaced with ionic liquid in the process of flotation. In addition, the best conditions were found based on the form 
of ternary ionic associate and the maximum flotation removal of ionic cadmium in the experiment. The effects of the experimental parameters were investigated and optimized. The method has high sensitivity and selectivity and can be used in the determination of $\mathrm{Cd}^{2+}$ in natural water.

\section{EXPERIMENTAL}

An ultraviolet visible spectrophotometer (UV-2550) was used to determine $\mathrm{Cd}^{2+}$ concentration at $572 \mathrm{~nm}$. The $\mathrm{pH}$ solution was measured by a Shengci model pHS-25 meter. Flotation carried out in a self-made flotation device which included a plexy glass column of $50 \mathrm{~cm}$ height and $3 \mathrm{~cm}$ diameter. The column contained a stonefilter (10-15 cm, porosity of 4$)$ at the bottom for producing small air bubbles. A nitrogen cylinder was used to generate air bubbles under $1.1 \mathrm{~atm}$ pressure and a rotary flowmeter (LZB/LZY) was also applied for control of gas flow rate.

Unless otherwise stated, all chemical reagents used in this study were of analytical grade. The standard stock solutions $\left(1.0 \times 10^{-4} \mathrm{~mol} / \mathrm{L}\right)$ was prepared from $0.1834 \mathrm{~g} \mathrm{CdCl}_{2}, 0.1659 \mathrm{~g}$ $\mathrm{KI}, 0.4790 \mathrm{~g}$, rhodamine $\mathrm{B}$, respectively in distilled water of $100 \mathrm{~mL}$ volumetric flask. A stock of $\mathrm{AcOH}$ solution of $0.1 \mathrm{~mol} / \mathrm{L}$ concentration was prepared by dissolving $5.72 \mathrm{~mL} \mathrm{AcOH}$ in distilled water of $100 \mathrm{~mL}$ volumetric flask. These standard aqueous solutions are used to form the ternary ionic associate $(\mathrm{RhB})_{2}\left(\mathrm{CdI}_{4}\right)$ [20]. The $\left(\mathrm{NH}_{4}\right)_{2} \mathrm{SO}_{4}$ solution, $38 \%$ mass fraction, was prepared by dissolving $152 \mathrm{~g}$ solid $\left(\mathrm{NH}_{4}\right)_{2} \mathrm{SO}_{4}$ in $248 \mathrm{~mL}$ distilled water for controling the iron strength. Ionic liquid $\left[\mathrm{Bmim}^{\mathrm{B}} \mathrm{BF}_{4}\right.$ was applied in the flotation recovery of the ternary ionic associate.

Briefly, each test contained $5 \mathrm{~mL}$ of $1.0 \times 10^{-4} \mathrm{~mol} / \mathrm{L} \mathrm{Cd}^{2+}$ ions. The content of $\mathrm{KI}$, rhodamine $\mathrm{B}(\mathrm{RhB})$ and $\mathrm{AcOH}$ stock solution in a certain order was combined with distilled water to make up $50 \mathrm{~mL}$. The solution was stirred for approximately 20 min to ensure consistent mixing of all reagents and react completely. It was transformed into the flotation column. The $38 \%$ mass fraction of $\left(\mathrm{NH}_{4}\right)_{2} \mathrm{SO}_{4}$ solution was filled. Because the density of ionic liquid was more than water, the mixed solution of ionic liquid and acetic ether (1:1) was used to extract the ternary ionic associate. Then bubble generation began just after the solution was introduced into the column and the gas flow rate was kept stable. The absorbency of solvent phase was determined at $572 \mathrm{~nm}$.

\section{RESULTS AND DISCUSSION}

Absorption curve: The absorption curve of rhodamine B $\left(1.0 \times 10^{-4} \mathrm{~mol} / \mathrm{L}\right)$, blank reagent and ionic liquid was determined and the absorption curve of ternary ionic associate solution was also determined. As shown in Fig. 1, the maximum absorption wavelength of rhodamine B was at $554 \mathrm{~nm}$ while the ternary ionic associate was at $572 \mathrm{~nm}$. Obviously, there is a red shift of wave crest, so determination was carried out at $572 \mathrm{~nm}$ in this work.

Effect of acetic acid: Fig. 2 shows the effect of $\mathrm{AcOH}$ on forming of the ternary associate. As it can be seen that with the increasing amount of $\mathrm{AcOH}$, the absorbency increased constantly from 1 to $8 \mathrm{~mL}$. The maximum absorbency was observed at $8 \mathrm{~mL}$ of $\mathrm{AcOH}$. Then, absorbency kept stable until $12 \mathrm{~mL}$. Fig. 2 also shows that after $12 \mathrm{~mL}$ of $\mathrm{AcOH}$, there are insignificant declines in absorbency as the amount of $\mathrm{AcOH}$ increases. So, the optimal amount of $\mathrm{AcOH}$ was set for $8 \mathrm{~mL}$.

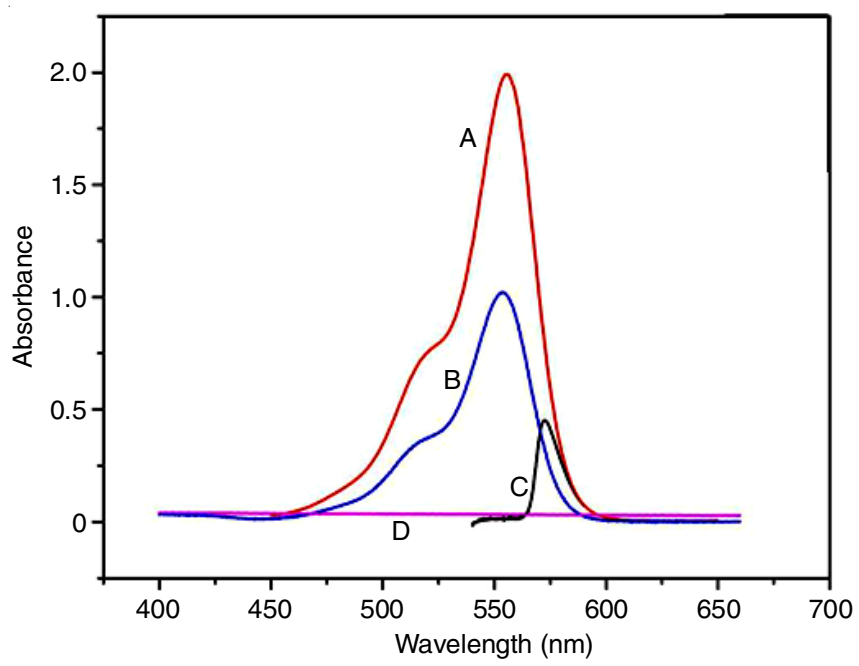

Fig. 1. Absorption curve

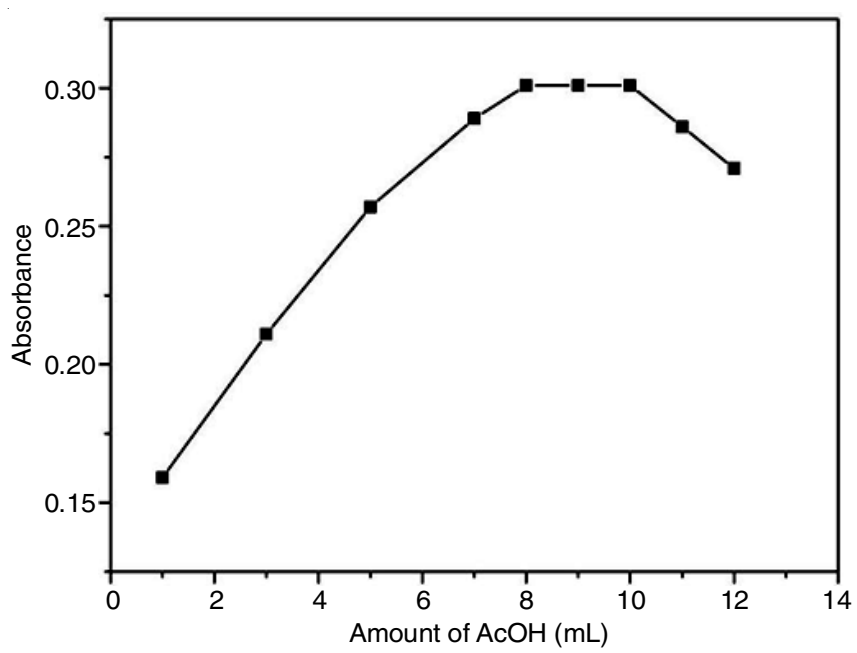

Fig. 2. Effect of AcOH

Effect of KI: The effect of standard solution of KI on forming the ternary associate was inspected. An increase in amount of KI resulted in an increase in absorbency from 10 $\mathrm{mL}$ to $20 \mathrm{~mL}$. The maximum absorbency occurred at $20 \mathrm{~mL}$. Afterwards, as the amount of $\mathrm{KI}$ increase after $20 \mathrm{~mL}$, the absorbency began to remain unchanged. Hence, the optimal amount of KI was set for $20 \mathrm{~mL}$.

Effect of rhodamine B: Fig. 3 shows the effect of the rhodamine $\mathrm{B}$ on forming the ternary associate. With the increasing amount of rhodamine B the absorbency increase constantly from 1 to $4 \mathrm{~mL}$ of rhodamine $\mathrm{B}$. The maximum absorbency was observed at $4 \mathrm{~mL}$ of rhodamine $\mathrm{B}$. Thus, the optimal amount of rhodamine $\mathrm{B}$ was set for $4 \mathrm{~mL}$.

Effect of reaction time: The effect of the reaction time was studied. As the reaction time increase, the absorbency increase steadily until $20 \mathrm{~min}$ and remain unchanged later. Apparently, the complete formation of ternary associate was a certain period of time. This was related to the reaction rate of chemical kinetics. Therefore, the optimal reaction time of ternary ionic associate was set for $20 \mathrm{~min}$.

Effect of flotation time: The maximum absorbency was observed at flotation time of $15 \mathrm{~min}$. After $15 \mathrm{~min}$ of flotation, the absorbency is stable in flotation efficiency of cadmium as 


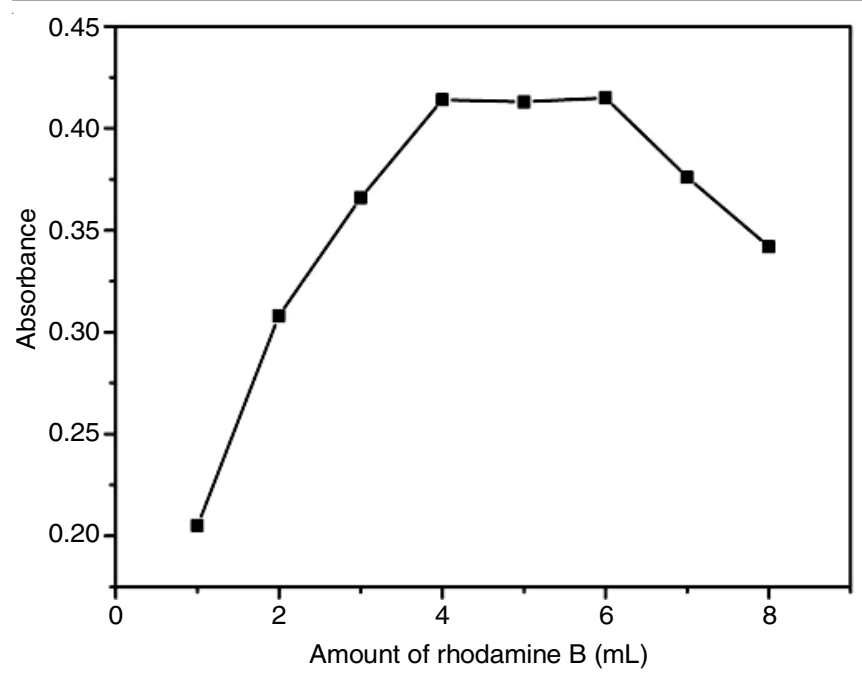

Fig. 3. Effect of rhadamine B

flotation time increases. The optimal flotation time was set for $15 \mathrm{~min}$.

Effect of air flow rate: With the air flow rate effect increasing, the absorbency increase constantly from 15 to $30 \mathrm{~mL} / \mathrm{min}$. The maximum absorbency was observed at $30 \mathrm{~mL} / \mathrm{min}$ of air flow rate effect. Hence, the optimal air flow rate was set for $30 \mathrm{~mL} / \mathrm{min}$.

Standard curve of flotation: The amount of $\mathrm{Cd}^{2+}$ was changed from 1 to $7 \mathrm{~mL}$ to participate in the flotation of optimal formation conditions. As shown in Fig. 4, the linear regression was kept from 1 to $7 \mathrm{~mL}$. The equation of linear regression was $y=0.04693 x+0.30629$, with $R^{2}=0.99407$.

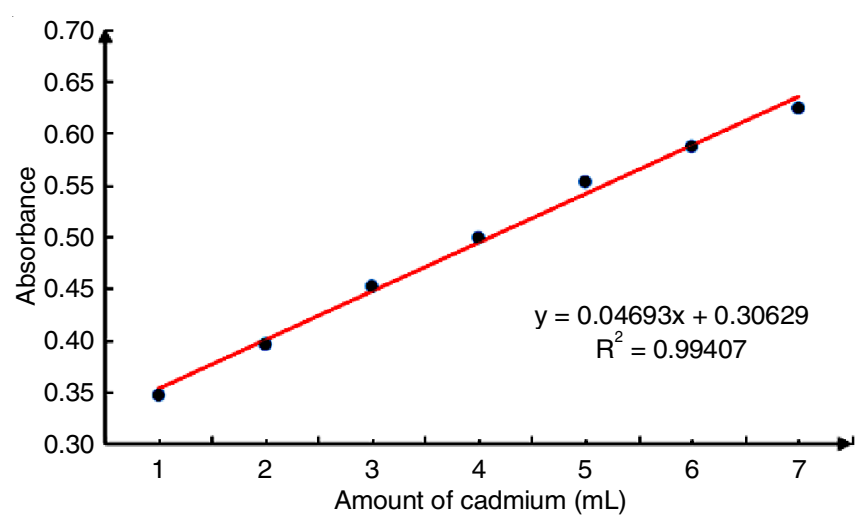

Fig. 4. Standard curve of flotation

Determination of cadmium(II) in wastewater sample: The wastewater was collected from the local farm area in order to detect the contents of $\mathrm{Cd}(\mathrm{II})$ ions and the results are compared to the standard experiment to the sample. The results are shown in Table-1.
TABLE-1

DETERMINATION RESULTS OF Cd(II) IN ENVIRONMENTAL WATER SAMPLE $(n=5)$

\begin{tabular}{|c|c|c|c|c|c|}
\hline $\begin{array}{l}\frac{0}{\tilde{a}} \\
\text { हूँ } \\
\text { हn }\end{array}$ & $\begin{array}{c}\text { Mean value } \\
(\mu \mathrm{g} / \mathrm{L}) \\
(\mathrm{n}=\mathrm{x})\end{array}$ & $\begin{array}{c}\operatorname{RSD}(\%) \\
(\mathrm{n}=5)\end{array}$ & $\begin{array}{l}\text { Added } \\
(\mathrm{mg} / \mathrm{L})\end{array}$ & $\begin{array}{c}\text { Total } \\
(\mathrm{mg} / \mathrm{L})\end{array}$ & $\begin{array}{c}\text { Recovery } \\
(\%)\end{array}$ \\
\hline 1 & 80.5 & 2.67 & 50.0 & 124.5 & 95.4 \\
\hline 2 & 64.3 & 3.12 & 50.0 & 119.4 & 104.4 \\
\hline 3 & 98.5 & 2.93 & 50.0 & 142.1 & 95.7 \\
\hline
\end{tabular}

\section{REFERENCES}

1. F. Fu and Q. Wang, J. Environ. Manage., 92, 407 (2011); https://doi.org/10.1016/j.jenvman.2010.11.011.

2. S.P. Liu, Z.F. Liu and H.Q. Luo, Anal. Chim. Acta, 407, 255 (2000); https://doi.org/10.1016/S0003-2670(99)00816-8.

3. L. Järup and A. Åkesson, Toxicol. Appl. Pharmacol., 238, 201 (2009); https://doi.org/10.1016/j.taap.2009.04.020.

4. M.H. Salmani, M. Davoodi, M.H. Ehrampoush, M.T. Ghaneian and M.H. Fallahzadah, Iran. J. Environ. Health Sci. Eng., 10, 16 (2013); https://doi.org/10.1186/1735-2746-10-16.

5. Q. Cheng and H. Dong, Mikrochim. Acta, 150, 59 (2005); https://doi.org/10.1007/s00604-005-0333-8.

6. M.K. Jha, V. Kumar, J. Jeong and J. Lee, Hydrometallurgy, 111-112, 1 (2012);

https://doi.org/10.1016/j.hydromet.2011.09.001.

7. C.W. Wong, J.P. Barford, G. Chen and G. McKay, J. Environ. Chem. Eng., 2, 698 (2014); https://doi.org/10.1016/j.jece.2013.11.010.

8. M. Aliabadi, M. Irani, J. Ismaeili, H. Piri and M.J. Parnian, Chem. Eng. J., 220, 237 (2013); https://doi.org/10.1016/j.cej.2013.01.021

9. M. Ghaedi, A. Shokrollahi, K. Niknam, E. Niknam, A. Najibi and M. Soylak, J. Hazard. Mater, 168, 1022 (2009); https://doi.org/10.1016/j.jhazmat.2009.02.130.

10. E.L. Silva, P.S. Roldan and M.F. Giné, J. Hazard. Mater, 171, 1133 (2009); https://doi.org/10.1016/j.jhazmat.2009.06.127.

11. E.L. Silva and P.S. Roldan, J. Hazard. Mater, 161, 142 (2009); https://doi.org/10.1016/j.jhazmat.2008.03.100.

12. T. Oymak, S. Tokalioglu, V. Yilmaz, Z. Kartal and D. Aydin, Food Chem., 113, 1314 (2009); https://doi.org/10.1016/j.foodchem.2008.08.064.

13. Z. Shahri, A. Sobhani and M. Salavati-Niasari, Mater. Res. Bull., 48, 3901 (2013); https://doi.org/10.1016/j.materresbull.2013.05.100.

14. H. Parham, N. Pourreza and N. Rahbar, J. Hazard. Mater, 163, 588 (2009); https://doi.org/10.1016/j.jhazmat.2008.07.007.

15. F. Xie, X. Lin, X. Wu and Z. Xie, Talanta, 74, 836 (2008); https://doi.org/10.1016/j.talanta.2007.07.018.

16. G. Absalan, M. Akhond and L. Sheikhian, Talanta, 77, 407 (2008); https://doi.org/10.1016/j.talanta.2008.06.049.

17. M.D. Joshi and J.L. Anderson, RSC Adv., 2, 5470 (2012); https://doi.org/10.1039/c2ra20142a.

18. C. Nerín, J. Salafranca, M. Aznar and R. Batlle, Anal. Bioanal. Chem., 393, 809 (2009); https://doi.org/10.1007/s00216-008-2437-6.

19. J.L. Anderson, D.W. Armstrong and G.T. Wei, Anal. Chem., 78, 2892 (2006); https://doi.org/10.1021/ac069394o.

20. T.D. Ho, C. Zhang, L.W. Hantao and J.L. Anderson, Anal. Chem., 86, 262 (2014); https://doi.org/10.1021/ac4035554. 